\title{
Real-time monitoring of the vadose zone as a key to groundwater protection from pollution hazard
}

\author{
O. Dahan \\ Zuckerberg Institute for Water Research, \\ Ben-Gurion University of the Negev, Israel
}

\begin{abstract}
Minimization subsurface pollution is very dependent on reliable and effective monitoring tools. Today, most monitoring programs are based on observation wells that enable collection of hydrological and chemical information from the saturated part of the subsurface. As a result, identification of pollution in wells is clear evidence that the contaminants already crossed the entire vadose-zone and accumulated in the aquifer. Accordingly, an effective monitoring program must include monitoring means that provide real-time information in the unsaturated zone. Such monitoring programs may provide "early warning" for potential pollution processes that may risk groundwater quality. A vadose-zone monitoring system (VMS), which was developed recently, allows continuous monitoring of the hydrological and chemical properties of percolating water in the deep vadose zone. Data which is collected by the system allows direct measurements of the water percolation fluxes and detects the chemical evolution of the percolating water across the entire unsaturated domain. The VMS is designed for long term continuous operation in a time scale of years to decades. To date, the system has been successfully implemented in several studies on water flow and contaminant transport in various hydrological and geological setups. These include research projects on: (a) floodwater infiltration and groundwater recharge from stream channels and reservoirs, (b) impact of various agricultural regimes on quality and quantity of groundwater recharge, (c) subsurface pollution of dairy farms, (d) chemical evolution of landfill leachates, and (e) control of remediation operations in contaminated sites.

Keywords: vadose zone monitoring, groundwater protection, contaminate transport, percolation.
\end{abstract}




\section{Groundwater protection from pollution hazard}

Groundwater is recognized as the most important water source in most parts of the world. The scarcity of surface water in arid and semiarid regions and its susceptibility to man-made pollution have driven a worldwide trend to prefer groundwater exploitation over that of surface water. This trend is pronounced even in regions where surface water is abundant such as Europe, North America and Asia $[1,2]$. One of the main driving forces for the increasing reliance on groundwater is related to the perception that groundwater is a "safe" water source which is relatively protected from immediate pollution events. It is assumed that slow flow processes in the vadose zone combined with natural attenuation processes protect groundwater pollution. Unfortunately, this perception has proven to be ill-founded: today, groundwater pollution from surface sources can be found in many aquifers, in association with industrial, agricultural or urban development.

Public and political awareness of the impact of subsurface pollution on the deterioration of groundwater resources and the consequent risk to public health has led to recognition of the need for active protection of groundwater resources from pollution origin on land surface [3]. Clearly, any efficient program for groundwater protection from potential pollution requires an efficient monitoring scheme that can provide reliable information on the hydrological and chemical status of the subsurface. Today, most of the traditional monitoring programs for the purpose of groundwater protection from pollution hazards are based on culling information from the groundwater. This information is usually retrieved from boreholes penetrating the saturated section of the groundwater. Accordingly, the entire path and fate of pollutants transported from land surface through the vadose zone to the groundwater is usually evaluated from the chemical and physical state of water sampled obtained from a well penetrating the aquifer. This type of monitoring procedure is well rooted in both scientific studies and legislative acts that enforce groundwater-monitoring programs wherever groundwater is endangered by potential sources of pollution $[4,5]$. However, by definition, monitoring the chemical state of the groundwater for the sake of protecting from potential pollution creates a paradox. Obviously, identification of contaminants in the groundwater means that contaminants have already crossed the entire vadose zone and polluted the aquifer. Since lateral flow in the groundwater is relatively slow processes, the appearance of a pollutant in a well may take years or even decades. Due to the long lag time between the initiation of a pollution event and its identification in the groundwater, the total mass of pollutant that has penetrated to the subsurface may be extremely high, creating a large contaminant plume. Moreover, pollution identification in a well usually reveals only the edges of a much larger pollutant plume. Often well-water samples represent an average value of a large volume of sampled according to the screen's configuration and the flow pattern from the aquifer layers. In addition natural hydrodynamic dispersion processes reduce concentrations at the plume edges. 
Soil and groundwater pollution appears to be having a huge economic impact. In addition to the direct loss of water resources, often polluted properties are considered "brownfields" properties whose development is restricted until a cleanup/remediation program is implemented and proven to be efficient, effective and safe [6]. Over the past decades tremendous capital investments were directed worldwide to remediation of contaminated groundwater. Unfortunately, only littles successes were recorded in field scale remediation setup, and the cost efficiency on these remediation operations is very limited. Accordingly, one must conclude that continuation of the current practices, where groundwater protection is dependent on monitoring of the groundwater quality through wells is inefficient. It is clear then, that an efficient and cost-effective monitoring scheme should be designed provide early warning on pollution processes long before contaminants accumulate in the groundwater.

Following the facts that identification of contaminants in a well is a direct and obvious indication that the groundwater is already polluted and today's groundwater remediation technologies are not efficient enough, it is clear that the groundwater cannot be protected if the monitoring effort is focused on the groundwater itself. Accordingly, monitoring for the sake of groundwater protection has to rely on monitoring systems that provide early warnings, before the contaminants crossed the water table. Thus, monitoring technology that aims at preventing accumulation of contaminants in groundwater has to provide realtime information on the quality of the percolating water in the vadose zone before contaminants have reached the groundwater. Accordingly, the battle to protect groundwater from pollution requires that a major portion of the monitoring effort be shifted to the vadose zone.

\section{Vadose-zone monitoring technology}

Assessment of water percolation and solute transport in the vadose zone is considered a major challenge in hydrologic sciences. It is often characterized by unstable flow that is highly sensitive to hydraulic, chemical and microbial conditions. Although the basic information that allows adequate characterization of flow and transport in a well-defined medium is relatively well known, the processes occurring in natural heterogeneous environments are still far from being clearly described or properly predicted. Apparently, the difficulty in characterizing water flow and contaminant transport in natural unsaturated zones at the field scale is intimately related to the instability of unsaturated flow [710]. In laboratory experiments where the flow characteristics through a welldefined medium may be controlled, accurate measurements and consequent close calibration of transport models may be achieved. However, in natural field conditions the lithologic heterogeneity as well as the erratic nature of water availability on land surface dictated frequent variation in the profile water content and consequent flow pattern [11-13]. In addition, natural variation in water content of the sediment derive dramatic changes in the chemical physical and biological state of the sediments, impacts oxygen availability, controls development of indigenous microbial communities, and alters redox potential of 
the sediment [14-16]. These variation are magnified in natural environment where the chemical composition of the percolating water (e.g. available dissolved organic matter and nutrients) are subjected to continuous changes due to natural hydrologic cycles [17]. Accordingly chemical transformation of percolating water and contaminant attenuation in undisturbed natural vadose zone is dynamically dependent on the complex hydrological chemical and biological state of the sediment.

The need for real-time information on the quality of percolating water led to the development of a vadose-zone monitoring system (VMS). The VMS is designed to provide in-situ continuous measurements of the hydraulic and chemical properties of the percolating water across the entire vadose zone, from land surface to the water table (Figure 1). The system has been previously presented in numerous publication $[16,18]$. Therefore only brief description will be presented here. In general, the VMS allows attachment of customized monitoring units to the side wall of an uncased small-diameter slanted borehole. It is composed of a flexible sleeve made of thin elastic liner, hosting several monitoring units along its length in the desired distribution (Figure 2). In the borehole, the monitoring units are aligned along the upper side wall facing the undisturbed sediment column which extends from the probe to the surface (Figure 1).

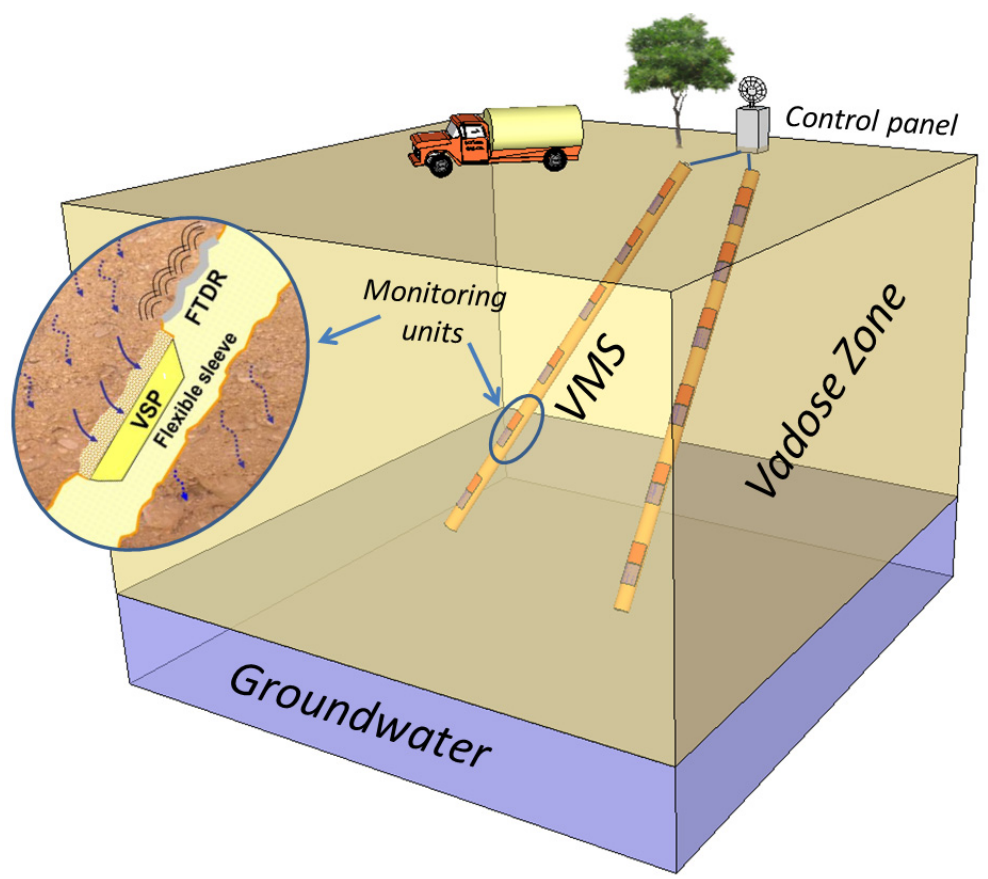

Figure 1: Schematic illustration of vadose zone monitoring systems (VMS) installed in the vadose zone and general structure of the monitoring units. 


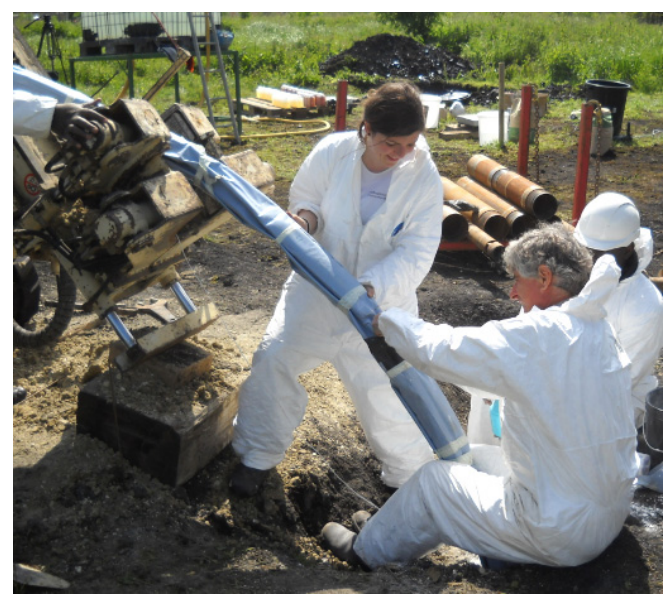

Figure 2: VMS installation in the vadose zone of a contaminated site subjected to remediation (Belgium, 2013).

Immediately after insertion of the sleeve into the borehole, it is filled with a solidifying liquid material, such as two-component urethane or concrete. Prior to curing, the hydrostatic pressure generated by the filling material expands the sleeve and tight contact between the monitoring units and the borehole walls is achieved. Consequently, the borehole is sealed all along its length as the sleeve expands to fill the entire void of the borehole, tension release cracks restore, and preferential flow along the borehole is prevented. Assuming that the general flow direction in the vadose zone is vertical, every point on the upper side of a slanted borehole faces an undisturbed sediment column. Each monitoring unit on the sleeve is composed of flexible time-domain reflectometry (FTDR) probe which allows continuous measurement of the temporal variations in the sediment water content [12, 13, 19], and vadose-zone sampling ports (VSPs) which allow frequent sampling of the vadose-zone pore water $[16,18]$ or measure its matric potential [20].

Up to now, the VMS has been successfully implemented in numerous studies on water flow and contaminant transport in the unsaturated zone in a variety of hydrological setups, including (1) flood water percolation in arid environments $[11,12,21]$, (2) rain water percolation through thick sand and clay formations $[13,22]$, (3) solute transport in the vadose zone $[15,16,18]$, (4) impact of agriculture on groundwater quality $[17,23]$, and interactive bio-remediation of contaminated vadose zone [24].

\section{Direct observations on flow and transport in the vadose zone}

Application of vadose zone monitoring systems in a wide range hydro-geological setups enabled detailed realization of the actual flow and transport processes that take place in the unsaturated zone. Apparently, data that was collected by the 
VMS allowed for the first time evaluation of few assumptions and common perceptions that that are often used in vadose zone hydrology. In the following, few of these perceptions will be reviewed in light of direct observation obtained by the VMS.

\subsection{Water percolation}

Several independent studies on water percolation through the unsaturated zone measured the direct impact of wetting events on land surface, such as rain, flood and irrigation, on the percolation process in the vadose zone. These studies were conducted through various hydraulic and geologic setups, ranging from rainwater infiltration in sandy and clay formations $[13,25]$ to flood water infiltration in alluvial rivers and reservoirs $[12,26]$. As expected, every wetting event on land surface launced a wetting front that propagate down the unsaturated zone. The wetting fronts propagation through the unsaturated zone was expressed a sequential increase in water content across the unsaturated sediment. Yet in all of the monitored sites, through hundreds individual infiltration events, percolation took place through a narrow range of water content amplitudes that did not exceed field capacity values. Low water content in the unsaturated zone were maintained regardless the hydrological conditions on land surface. Saturation was never achieved due to percolation even if the surface was flooded with high water head for long periods [12, 27]. Moreover, saturation was achieved only due to water table rise into the unsaturated zone and never due to down percolation.

Active infiltration and groundwater recharge under low water content is well demonstrated in Dahan et al. [12], where flood water infiltration from alluvial river were monitored trough several flood events. In this particular example water content variations in the vadose profile were measured continuously during a flood event which lasted for four days (Figure 3). The results indicate sequential wetting of the vadose zone cross section and gradual propagation of the wetting fronts that allow direct calculation of the flow velocity and fluxes. Yet, although the sediment underlying the stream channel where characterizes as homogeneous coarse sands and the river was flooded for couple of days with peak head stage of $1.5 \mathrm{~m}$, no saturation was recorded in any part of the vadose zone throughout the entire flood duration, even close to the land surface. Note, that volumetric water content remain low $(<13 \%)$ even after long flooding duration and under the high water heads. Saturation $(\sim 30-40 \%)$ was achieved only upon up-rise of the water table into the vadose zone.

The limited capacity of infiltration in the unsaturated zone which is emphasized through the percolation under a narrow range of relatively low water content impacts also water fluxes and ground water recharge rates. Detailed analysis of the percolation process through several flood events under various flood heads, ranging from 0.2 to $3 \mathrm{~m}$, revel that infiltration flux is relatively independent on flooding stage and provide relatively constant flux under all water heads. It has been suggested that natural micro-layer structure of the sediment, even in material such as sand dune that appear very homogeneous 

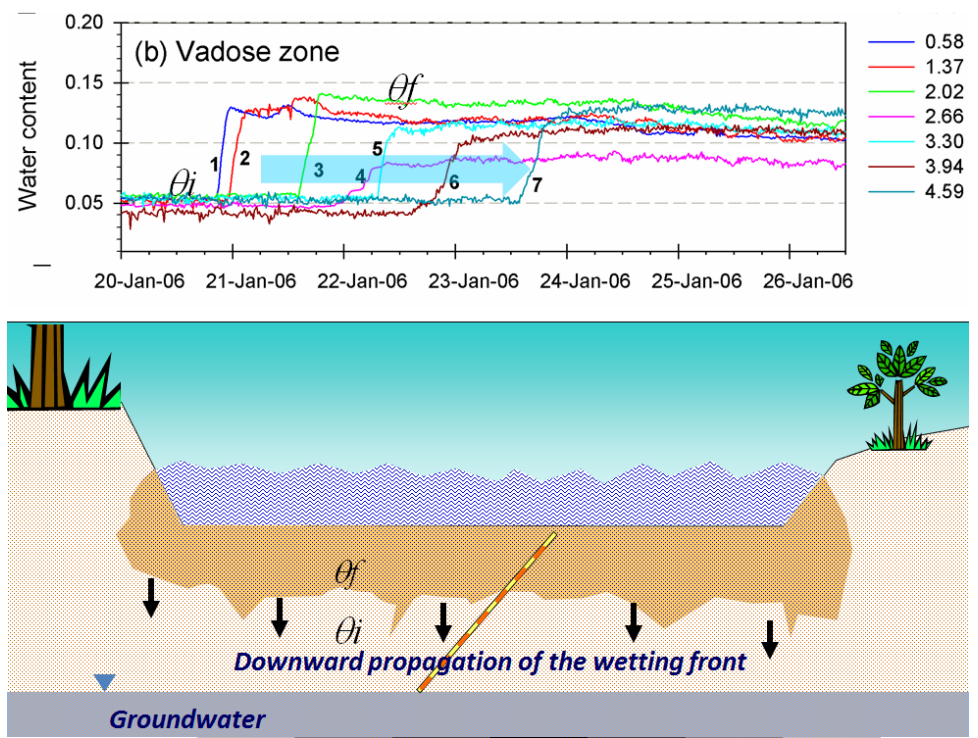

Figure 3: Temporal variation in water content of sediment from the vadose zone underlying an ephemeral river in Namibia during a flood event (after Dahan et al. [12]). The sequential wetting of the vadose zone enable direct assessment of flow velocity and water fluxes in the unsaturated zone.

through sedimetologic analysis, create significant anisotropy which limits the percolation and regulated the fluxes. Both phenomenon, percolation under limited saturation degree and limited percolation value that are independent on surface head were recorded by the VMS also in other sites under similar conditions $[11,18,26,28]$ has a great implication on flow models.

\subsection{Solute transport}

Water flow and solute transport in homogeneous porous sediment, such as sand, is often treated using advection dispersion models. It is assumed that under stable matrix flow conditions, lateral mixing processes are fast in relation to vertical convective transport [29]. As such, it is assumed that during uniform flow, at or close to equilibrium exists between the different types of pores in the sediments [30]. On the other hand, non-equilibrium flow is often attributed to preferential flow that is controlled by macro-pores, such as fractures and wormholes [31].

A research study on the dynamic of water percolation and solute transport through an unsaturated sandy formation was conducted using a vadose-zone monitoring systems [13]. Continuous measurements of the temporal variations in vadose-zone water content as well as frequent sampling of the vadose-zone pore water allowed detailed tracking of the wetting fronts propagation velocities and determination of the flow patterns governing solute transport. It has been shown 
that the chemical composition of mobile flowing water along the vadose zone is not in chemical equilibrium with the total soluble solute potential of the sediment (Figure 4). Major differences between the chemical composition of the mobile flowing phase, which is sampled by the VSPs, and the total solute potential, which is measured through water extracts of sediment samples, were observed through long sampling periods. This phenomenon is usually attributed to a flow mechanism controlled by preferential flow. However, wetting-front propagation patterns, as monitored continuously over several rainy seasons through the entire vadose zone, as well as a tracer experiment, showed relatively uniform wettingfront propagation with no direct evidence for significant preferential flow. Contradictory observations on matrix and preferential flow as governing mechanisms led to conceptualization of the percolation process as pore-scale dual domain flow. Coexistence of two phases within the sediment pores that are not hydraulically connected and do not reach chemical equilibrium is well supported by results from extensive monitoring of a deep vadose zone [15, 21]. Today interpretation of the flow and transport processes from the chemical composition of sediment samples is a common methodology in vadose zone hydrology. Nevertheless, these observations suggest that this method do not properly represent the actual hydrological and transport processes that take place in the unsaturated zone.

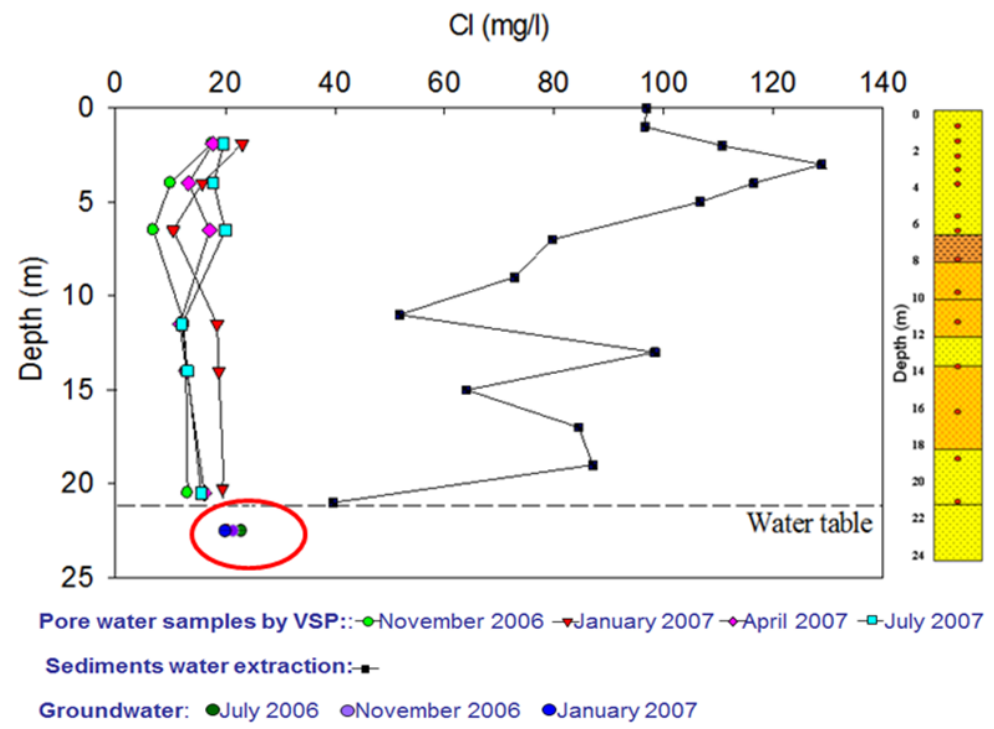

Figure 4: Chloride-concentration profiles along the vadose zone as obtained from sediment extraction and continuous sampling by the VMS, together with chloride concentration in the local groundwater. The differences in salinity profiles emphasize that the mobile flowing water is not in chemical equilibrium with the sediment (after Rimon et al. [16]). 


\subsection{Impact of clay layers on water flow in the unsaturated zone}

Heavy clay soils are regarded as less permeable due to their low saturated hydraulic conductivities. Accordingly such soils are perceived safe in prevention groundwater pollution. Water percolation dynamics and contaminate transport through clayey vadose zone was studies using several vadose-zone monitoring systems which enabled continuous measurements of the temporal variation in vadose zone water-content profiles and frequent sampling of the vadose zone pore water $[15,25,32]$. Results from four years of continuous measurements showed quick rises in sediment water content following rain events and temporal wastewater overflows. The percolation pattern indicated dominance of preferential flow through a desiccation-crack network crossing the entire clay sediment $(>13 \mathrm{~m})$. High water-propagation velocities $(0.8$ to $8 \mathrm{~m} \mathrm{~h}-1)$ were observed, indicating that the desiccation-crack network remains open and serves as a preferential flow pathway year-round, even at high sediment water content $\left(\sim 50 \mathrm{~m}^{3} \mathrm{~m}^{-3}\right)$. The natural formation of desiccation-crack networks induces rapid infiltration of raw waste to deep sections of the vadose zone, bypassing the sediment's most bio-geo-active parts, and jeopardizing groundwater quality. Comparison of the dynamics of water percolation in heavy clay sediment $(>50 \%$ clay content) with that of other sites such as sand dunes [13] and alluvial stream beds $[11,12]$ reveals that water percolation in unsaturated clay sediment is several orders of magnitude faster compare to any other sediment formation that was measured including sand dunes (Figure 5). Direst observation on fast infiltration through clay formation in the unsaturated zone were also monitored in other studies where the VMS was used [13, 23, 33]. Obviously these observations indicate that unsaturated clay formations are more susceptible for pollution compare with other such as sand and even gravely alluvium which are often perceived more permeable compare with clay.

\section{Vadose-zone monitoring and groundwater protection}

Standard traditional groundwater-monitoring with observation wells fail to provide information that is essential for protecting groundwater from pollution that originates on land surface. As a result, detection of polluted groundwater in monitoring wells is always clear evidence that the pollutants have already crossed the entire vadose zone and accumulated in the aquifer. Accordingly, protection of groundwater from potential pollution originating on land surface has to include effective and continuous monitoring of the vadose zone. Such monitoring systems should be operated as an alarm system that can provide early warnings on pollution events. Identification of pollution process in its early stages in the vadose zone is crucial in prevention of groundwater pollution. Today substantial scientific and economic efforts are invested worldwide in remediation of contaminated aquifers. Nevertheless, remediation of contaminated aquifers to standard drinking-water levels is not feasible. Therefore, some of the monitoring effort should be shifted to the vadose zone 


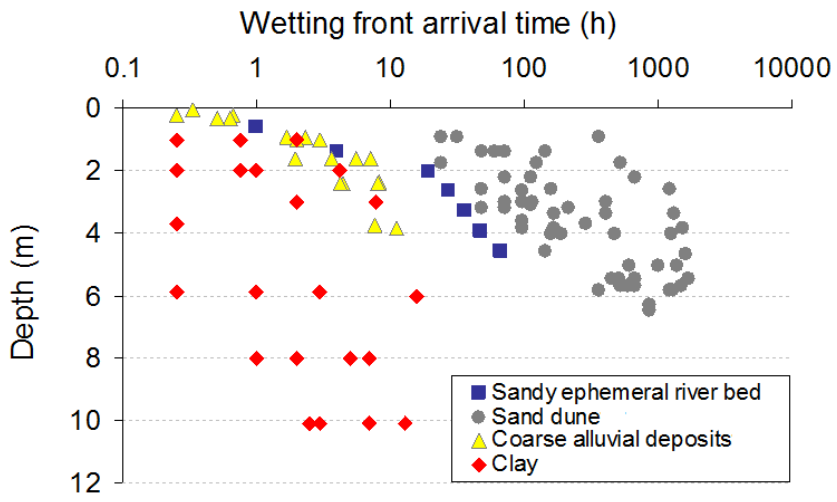

Figure 5: Propagation of wetting fronts under a sandy ephemeral riverbed during flood events (after Dahan et al. [12]), under a sand dune during natural rain events (after Rimon et al. [13]), under a coarse alluvial ephemeral riverbed during flood events (after Dahan et al. [11]), and under dispersive clay soil (after Baram et al. [14]). The data points represent the lag time between the initiation of every rain or flood event on land surface and the time of increase in sediment water content at each depth.

where pollution events may be monitored at their early stages long before creation of large pollution plums in groundwater turns inevitable. The VMS presented here (and in other publications cited in this manuscript) shows that continuous monitoring of the vadose zone's hydraulic and chemical properties is feasible and should be further developed for the sake of groundwater protection from potential pollution.

\section{References}

[1] http://web.worldbank.org, "The Briefing Note Series on Groundwater management".

[2] http://www.unep.org, "United Nation Environment Programme, Global Environment Outlook".

[3] http//www.epa.gov, "Handbook of Groundwater Protection and Cleanup Policies for RCRA Corrective Action for Facilities".

[4] B. J. Russell and J. S. Jon, No Practical Handbook of Soil, Vadose Zone, and Groundwater contamination: Assessment prevention and remediation. Lewis, 2004.

[5] http://eur-lex.europa.eu, "European Union Law".

[6] http://www.epa.gov/brownfields, "Brownfields and Land Revitalization".

[7] O. Dahan, R. Nativ, E. M. Adar, B. Berkowitz, and Z. Ronen, "Field observation of flow in a fracture intersecting unsaturated chalk," Water Resour. Res., vol. 35, no. 11, pp. 3315-3326, 1999. 
[8] O. Dahan, R. Talby, Y. Yechieli, E. Adar, N. Lazarovitch, and Y. Enzel, "In Situ Monitoring of Water Percolation and Solute Transport Using a Vadose Zone Monitoring System," Vadose Zo. J., vol. 8, no. 4, p. 916, 2009.

[9] D. Or, "Scaling of capillary, gravity and viscous forces affecting flow morphology in unsaturated porous media," Adv. Water Resour., vol. 31, no. 9, pp. 1129-1136, 2008.

[10] Z. Wang, W. A. Jury, A. Tuli, and D. J. Kim, "Unstable flow during redistribution: Controlling factors and practical implications," Vadose Zo. J., vol. 3, no. 2, pp. 549-559, 2004.

[11] O. Dahan, Y. Shani, Y. Enzel, Y. Yechieli, and A. Yakirevich, "Direct measurements of floodwater infiltration into shallow alluvial aquifers," $J$. Hydrol., vol. 344, no. 3-4, pp. 157-170, 2007.

[12] O. Dahan, B. Tatarsky, Y. Enzel, C. Kulls, M. Seely, and G. Benito, "Dynamics of flood water infiltration and ground water recharge in hyperarid desert," Ground Water, vol. 46, no. 3, pp. 450-461, 2008.

[13] Y. Rimon, O. Dahan, R. Nativ, and S. Geyer, "Water percolation through the deep vadose zone and groundwater recharge: Preliminary results based on a new vadose zone monitoring system," Water Resour. Res., vol. 43, no. 5, 2007.

[14] S. Baram, S. Arnon, Z. Ronen, D. Kurtzman, and O. Dahan, "Infiltration Mechanism Controls Nitrification and Denitrification Processes under Dairy Waste Lagoon," J. Environ. Qual., vol. 41, no. 5, pp. 1623-1632, 2012.

[15] S. Baram, Z. Ronen, D. Kurtzman, C. Külls, and O. Dahan, "Desiccationcrack-induced salinization in deep clay sediment," Hydrol. Earth Syst. Sci., vol. 17, no. 4, pp. 1533-1545, Apr. 2013.

[16] Y. Rimon, R. Nativ, and O. Dahan, "Physical and Chemical Evidence for Pore-Scale Dual-Domain Flow in the Vadose Zone," Vadose Zo. J., vol. 10, no. 1, p. 322, 2011.

[17] O. Dahan, a. Babad, N. Lazarovitch, E. E. Russak, and D. Kurtzman, "Nitrate leaching from intensive organic farms to groundwater," Hydrol. Earth Syst. Sci. Discuss., vol. 10, no. 7, pp. 9915-9941, Jul. 2013.

[18] O. Dahan, R. Talby, Y. Yechieli, E. Adar, N. Lazarovitch, and Y. Enzel, "In Situ Monitoring of Water Percolation and Solute Transport Using a Vadose Zone Monitoring System," Vadose Zo. J., vol. 8, no. 4, pp. 916925, 2009.

[19] O. Dahan, E. V McDonald, and M. H. Young, "Flexible Time Domain Reflectometry Probe for Deep Vadose Zone Monitoring," Vadose Zo. J., vol. 2, no. 2, pp. 270-275, 2003.

[20] Y. Rimon, R. Nativ, and O. Dahan, "Vadose Zone Water Pressure Variation during Infiltration Events," Vadose Zo. J., vol. 10, no. 3, pp. 1105-1112, 2011.

[21] Y. Amiaz, S. Sorek, Y. Enzel, and O. Dahan, "Solute transport in the vadose zone and groundwater during flash floods," Water Resour. Res., vol. 47, 2011. 
[22] S. Baram, D. Kurtzman, and O. Dahan, "Water percolation through a clayey vadose zone," J. Hydrol., vol. 424-425, pp. 165-171, Mar. 2012.

[23] T. Turkeltaub, O. Dahan, and D. Kurtzman, "Investigation of Groundwater Recharge under Agricultural Fields Using Transient Deep Vadose Zone Data," Vadose Zo. J., vol. 13, no. 4, 2014.

[24] E. Moshkovich, "Interactive Bioremediation of Fuel Contamination in the Deep Unsaturated Zone," Ben Gurion University of the Negev, 2014.

[25] S. Baram, D. Kurtzman, and O. Dahan, "Water percolation through a clayey vadose zone," J. Hydrol., vol. 424-425, pp. 165-171, Mar. 2012.

[26] Y. Shani, "Floodwater Percolation and Groundwater Recharge in Wadi Arava, Israel," Ben-Gurion University of the Negev, Israel, 2006.

[27] Y. Amiaz, S. Sorek, Y. Enzel, and O. Dahan, "Solute transport in the vadose zone and groundwater during flash floods," Water Resour. Res., vol. 47, no. 10, Oct. 2011.

[28] B. Tatarsky, "Dynamics of floodwater infiltration and groundwater recharge beneath ephemeral channels in arid regions, South-West Africa," Ben-Gurion University of the Negev, Midreshet Ben Gurion, 2008.

[29] W. A. Jury and H. Fluhler, "Transport of Chemicals through Soil Mechanisms, Models, and Field Applications," Adv. Agron., vol. 47, pp. 141-201, 1992.

[30] J. Simunek, N. J. Jarvis, M. T. van Genuchten, and A. Gardenas, "Review and comparison of models for describing non-equilibrium and preferential flow and transport in the vadose zone," J. Hydrol., vol. 272, no. 1-4, pp. $14-35,2003$.

[31] N. J. Jarvis, "A review of non-equilibrium water flow and solute transport in soil macropores: principles, controlling factors and consequences for water quality," Eur. J. Soil Sci., vol. 58, no. 3, pp. 523-546, 2007.

[32] S. Baram, S. Arnon, Z. Ronen, D. Kurtzman, and O. Dahan, "Infiltration mechanism controls nitrification and denitrification processes under dairy waste lagoon.," J. Environ. Qual., vol. 41, no. 5, pp. 1623-1632, 2012.

[33] S. Arnon, O. Dahan, S. Elhanany, K. Cohen, I. Pankratov, A. Gross, Z. Ronen, S. Baram, and L. S. Shore, "Transport of testosterone and estrogen from dairy-farm waste lagoons to groundwater," Environ. Sci. Technol., vol. 42 , no. 15 , pp. 5521-5526, 2008. 